\title{
Revista Brasileira de Enfermagem REBEn \\ Fragmentos da História de Enfermagem: um saber que se cria na teia do processo da submissão teórica
}

\author{
Fragments of Nursing History: a knowledge created in the web \\ of the theoretical submission process \\ Fragmentos de la História de la Enfermería: un saber que se crea \\ en la tela del proceso de la sumisión teórica
}

\section{Valéria Lamb Corbellini}

Enfermeira. Mestre e Doutora em Educação. Professora Adjunto e Coordenadora do Curso de Graduação em Enfermagem da Pontifícia Universidade Católica do Rio Grande do Sul (PUCRS), Porto Alegre, RS. vlamb@pucrs.br Artigo adaptado e elaborado a partir de uma das
análises de discurso da Tese de Doutorado: “0
Disciplinamento dos Saberes como Jogos de Verdades
no Ensino de Graduação em Enfermagem". Tese de
Doutorado em Educação da Faculdade de Educação da
Pontifícia Universidade Católica do Rio Grande do Sul
(PUCRS), orientado pela Profa. Dra. Marilú Fontoura de
Medeiros.
Submissão: $24 / 08 / 2006$ Aprovação: $15 / 12 / 2006$

\section{RESUMO}

Esta pesquisa teve como objetivo resgatar, a partir da década de 1950, no RS, práticas discursivas e não discursivas, de como o ensino de enfermagem foi se redesenhando, na busca de uma profissão mais científica, menos tecnicista e como as teorias de enfermagem tiveram participação nesse processo de transformações e contradições. $O$ estudo envolveu enfermeiras docentes que vivenciaram esse período da história e, para a análise documental, foi utilizada a análise de discurso. Uma das análises aponta a importância que as teorias de enfermagem tiveram na validação do saber/fazer da enfermeira, entre as décadas de 1950 e 1980.

Descritores: Educação em enfermagem; Ensino; História da enfermagem.

\section{ABSTRACT}

The purpose of this research is to rescue from the 1950s onwards, in the State of Rio Grande do Sul, both the discursive and non-discursive practices, on how the nursing teaching went on being redesigned, in search of a profession that would be more scientific, less technicistic, and how the nursing theories had had a participation in such process of transformations and contradictions. The survey has involved teaching nurses that had lived that period in history and, the discourse analysis was used for the documentary analysis. One of the analyses points out the importance of the nursing theories in the validation of the nurse's know-how between the 1950s and the 1980s.

Descriptors: Education, nursing; Teaching; History of nursing.

\section{RESUMEN}

Esta investigación tuvo por objectivo rescatar, a partir de la década de 1950, en RS, las prácticas discursivas y no discursivas de cómo la enseñanza de enfermería fue rediseñada, en la busqueda de una profesión más científica, menos tecnicista y como las teorías de enfermería tuvieron participación en este proceso de transformación y contradicciones. El estudio involucró enfermeras docentes que vivenciaron ese periodo de la historia y, para análisis documental, fue usado el análisis del discurso. Uno de los análisis apunta la importancia que las teorías de enfermería tuvieron en la validez del saber/hacer de la enfermera, entre las décadas de 1950 y 1980.

Descriptores: Educación en enfermería; Enseñanza; Historia de la enfermería.

Corbellini VL. Fragmentos da História de Enfermagem: um saber que se cria na teia do processo de submissão teórica. Rev Bras Enferm 2007 mar-abr; 60(2):172-7.

\section{INTRODUÇÃO}

Até a década de 1950, o ensino da Enfermagem, no Brasil, estava centrado no fazer. Os manuais de técnicas ${ }^{(1)}$, eram as bíblias dos estudantes. A habilidade manual, a capacidade de memorização, a postura na realização das técnicas, além do capricho, organização e perfeição, eram aspectos imprescindíveis, avaliados no ensino.

Na década de $1960^{(2)}$, a Enfermagem buscou a cientificidade, por meio das técnicas, mas a sua base científica era fundamentada no saber da Medicina. Nesse período, o ensino e a prática estavam cada vez mais distantes, "(...) favorecendo as contradições e o agravamento da crise de identidade da Enfermagem"(1).

Se fizermos uma análise desse período, até a década de 1980, observamos que a técnica prevalecia no fazer da enfermeira; entretanto, existia um saber, como bem diz Foucault, sujeitado, que foi construído ao longo da sua trajetória profissional e que partiu de uma prática, por ter sido uma profissão fortemente alicerçada no fazer, considerado no campo da Saúde como um conjunto de "saberes hierarquicamente inferiores", "saberes desqualificados pela hierarquia do conhecimento ou da cientificidade requeridas"(3). 
A enfermeira, ao mesmo tempo em que se sujeitou a essa prática, também sujeitou outros saberes, tanto com sua equipe, nos cuidados dos pacientes, como, também com alunos, entre outros. São práticas que instituem saberes e teorias.

Desta forma, quando se fala dos saberes históricos de lutas e dos populares, que a Enfermagem iniciou, a partir da década de 1980, na busca de um saber diferencial, local e particular, ela desqualifica a prática e parte em busca de um conhecimento teórico, como se a prática não fosse teoria. Contudo, não foi um saber isolado, houve toda uma prática discursiva, resultado de lutas na formação deste que gerou relações de poder, adquiridas pelo saber das massas, sejam elas instituições hospitalares, instituições de ensino, instituições comunitárias.

Nesta perspectiva, esse artigo tem como objetivo resgatar, a partir da década de 1950, no RS, práticas discursivas e não discursivas, de como 0 ensino de enfermagem foi se redesenhando e de como as teorias de enfermagem tiveram um papel importante nesse processo de transformações e contradições, quanto às relações com o campo de conhecimento e de disciplinamento, em sua luta por um espaço crítico e específico para a profissão.

\section{METODOLOGIA}

Ametodologia desenvolvida foi baseada na Arqueologia, Genealogia e na História Oral. Pelo método arqueológico as ordens de saber são encontradas na formação discursiva de uma determinada época. Pelo método genealógico, pode-se criticar e descrever a trajetória das transformações discursivas. A História oral dispõe de um meio de transformar tanto o seu conteúdo quanto sua finalidade, revelando novos campos de investigação.

\subsection{Acontecimentos que orientaram essa caminhada...}

$O$ estudo envolveu enfermeiras com idade acima de 60 anos, que foram ou ainda são docentes de uma Faculdade de Enfermagem, para ir à procura da regularidade na dispersão, ou seja, "(...) ir à busca de uma nova regularidade na proliferação dos saberes"(4).

\subsection{Buscando novos discursos nesta geografia a ser trilhada...}

A entrevista narrativa foi uma das modalidades de coleta. Outras formas de trilhar em busca de novos enunciados foram por análise documental em alguns Anais dos Congressos Brasileiro de Enfermagem, assim como, análise de reportagens em revistas, jornais, da década de 2000 , entre outros, sempre a partir de questionamentos do presente.

\subsection{Análise Foucaultiana de Discurso}

Ao escolher Foucault como fio condutor, não poderia deixar de eleger como análise documental, o discurso. Para tanto, realizar a análise de um discurso exigiu, por parte do pesquisador, uma atitude, no mínimo, de arqueologista, ou seja, a de esquadrinhar os enunciados, sejam eles de entrevistas, de documentos, revistas, jornais, de interlocutores anônimos, da mídia etc.

\subsection{Considerações Éticas}

Antes de iniciar as entrevistas, respeitando os aspectos éticos, conforme Resolução 196/96 do Conselho Nacional de Saúde ${ }^{(5)}$ e aprovado pelo Comitê de Ética da Universidade, apresentei a cada enfermeira o termo de consentimento livre e esclarecido. Após a leitura, o termo foi assinado pela participante e pela pesquisadora, em duas vias, para que cada uma ficasse com uma cópia. As entrevistas foram gravadas e transcritas pela pesquisadora.

\section{RESULTADOS E DISCUSSÃO}

Sabemos como nos sinaliza Foucault, que nenhum saber é neutro e, segundo ele, com a insurreição dos "saberes sujeitados", ou seja, "(...) uma série de saberes que estavam desqualificados como não conceituais, como insuficientemente elaborados, hierarquicamente inferiores, abaixo do nível do conhecimento ou da cientificidade requeridos"(6) e o qual ele denominou de "saber das pessoas", foi possível dar voz a esses saberes que incluiu 0 doente, a enfermeira, entre outros.

Essa relação teoria/prática, Foucault visualiza como relação muito mais parcial e fragmentada, ou seja, para ele, uma teoria só forma um corpo, quando há revezamento de uma prática à outra e a prática só se constrói como saber, quando esse revezamento ocorre de uma teoria para a outra. $\mathrm{E}$ ao lhe dar voz, ele pontua: “(...) é por isso que a teoria não expressará, não traduzirá, não aplicará uma prática; ela é uma prática"(3).

Nesse sentido, a contribuição que os estudos históricos têm para nos proporcionar se dá pela possibilidade de um repensar, a partir de uma prática, dando visibilidade aos conhecimentos produzidos em suas relações de saber e poder e das nossas ações como enfermeiras e docentes. "A experiência continuada de repensar e de fazer análises críticas do passado, atribui àqueles que a vivem a capacidade de refletir criticamente sobre a realidade e de ter uma visão menos simplista dos nexos entre passado, presente e futuro"(7).

Para exemplificar poderíamos citar alguns saberes, como, técnica de higiene corporal, higiene oral e mudança de decúbito para evitar úlceras de pressão, foram constituídas pela enfermagem e, com o tempo, ao passarem por um disciplinamento, foram classificados como sujeitados ou menos qualificados pela própria enfermeira e, nesse caso, também não "a sua altura".

A fala de Sol expressa o quanto eram valorizados esses saberes:

Eu me lembro, (década de 1960), que nós usávamos muito o CPE (Cuidado Preventivo de Escara). Nós analisávamos a situação do paciente e nós mesmos prescrevíamos esse CPE no relatório e outros cuidados como banho de leito. Tudo isso era escrito e nós exercitávamos e desenvolvíamos de uma maneira muito, como vamos dizer, nós reconheciamos, nós éramos bem felizes, reconheciamos que nós estávamos trazendo um cuidado diferente para o paciente. Nós tínhamos esta certeza e a equipe médica e de enfermagem também, pois era dito para nós e, eu não me lembro de nenhum paciente nosso ter adquirido escara, na unidade.

Ao mesmo tempo em que esse saber as tornava satisfeitas com os resultados obtidos, com o tempo, elas mesmas o desqualificarame, atualmente, são renegados pela maioria das enfermeiras como saberes inúteis por não envolver uma cientificidade que valide perante a sociedade como uma competência nobre, indo em busca da mesma especialidade médica, para ações de ponta, para a especificidade.

Na academia, quando essas técnicas são ensinadas aos alunos, percebese que eles desvalorizam e logo questionam que esta atividade não é de competência da enfermeira e que estão aprendendo para depois supervisionar o técnico/auxiliar de enfermagem quando realizarem esse procedimento. Eles já desqualificam na Graduação, passando para outro profissional, um conhecimento renegado.

Nesse sentido, o saber da enfermeira iniciou atrelado à higiene e ao conforto do paciente e, ao mesmo tempo em que elas valorizavam essas atividades como inerentes a sua profissão, também tinham consciência de que eles eram realizados de forma artesanal e, para torná-los acadêmicos era preciso (...) mudar os procedimentos de uma maneira artesanal para procedimentos científicos que não fizessem infecção no paciente e desse conforto. (SOL)

Porém, elas se deram conta de que somente o conhecimento adquirido na Universidade não proporcionaria o reconhecimento de um saber qualificado. Era preciso buscar outros territórios, outros espaços geográficos, e como algumas enfermeiras haviam feito estágio nos EUA, tiveram oportunidade de conhecer as primeiras teorias de Enfermagem que estavam sendo desenvolvidas naquele país, experiência verbalizada por Brisa em seu 
discurso:

(...) Mais tarde fui para o Exterior fazer outros cursos, nos EUA (década de 1960). Foi muito boa à experiência, voltei mais segura e vi como era o negócio, muito do que eles escreviam, nós começamos a aplicar aqui no Brasil, como as teorias de Enfermagem.

Nesse sentido, ao se perceber como parte da necessidade de se "formar", para melhor qualificar o seu conhecimento, ela vai em busca de uma formação na linha da importação de saberes. Foram práticas incorporadas no ser enfermeira que para adquirir um "status" na hierarquia dos saberes era preciso se qualificar no Exterior, mais precisamente nos EUA.

Essa ação de conquista de si passou por um ser conquistado por idéias que circulavam em núcleos mais "avançados", como sendo um bebedouro. Esse trazia a água, a saciedade, o bem-estar, a segurança, o sentir-se mais forte, como bem nos sinalizou Brisa:

"Quando voltei dos EUA, disse: 'agora, vamos dispensar os médicos, agora é a Enfermagem mesmo', por que eu voltei segura".

A necessidade de ter maior segurança e autonomia no seu agir passava por esse disciplinamento de saberes. Era preciso "se apresentar", aos outros profissionais e principalmente, aos médicos, que elas detinham um saber reconhecido internacionalmente e, assim, poderiam desenvolver a sua profissão, sem se sentirem desqualificadas, perante o saber deles.

Brisa, também verbalizou que esse "ritual de passagem" ocorreu de maneira tranqüila, mas, foi preciso "pedir permissão" para começarem a desenvolver as suas atividades com mais autonomia, como ela nos diz:

(...) Essa transição foi tranqüila, porque nós conversamos com eles (médicos) e eles tinham confiança (...) (Brisa).

Que confiança era essa que eles depositaram na enfermeira? Seria a de que, com essa qualificação no Exterior, elas teriam maior competência para cuidar de "seus pacientes?" Ou poderiam assumir disciplinas no Curso de Graduação, que até então, eram ministradas por médicos?

Rosa-dos-Ventos, que também fez especialização no Exterior, ilustra uma situação ocorrida, no período de quando foi Diretora de uma Escola de Enfermagem, em relação a essas hierarquias de saberes:

Eu tinha autonomia, enquanto Diretora (...), porque a Escola foi anexa da Faculdade de Medicina durante muitos anos, e quando eu estava na direção, à luta que nós tínhamos era enorme. Nós éramos muito bem recebidas, mas nós queríamos nossa independência, uma faculdade independente, e eu me lembro que o professor, eu passei por várias diretorias, e o brabo do Diretor da Medicina, ele mantinha o seu raciocino, me lembro que uma vez iria chegar uma visita americana, vinham muitos americanos aqui, essas coisas que encantavam eles aqui, e ele mandou me chamar 'A Sra. vai me ajudar hoje, nós vamos receber um americano e o meu inglês está muito ruim, a Sra.está recém chegando de lá, a Sra. vai me ajudar (...), não? ', está bem então, eu fui no grupo pra mostrar a eles o que a faculdade tinha. A gente fazia o que era possivel(...)

A palavra "autonomia" iniciada no discurso de Sol e que aparece em vários momentos nos discursos das outras entrevistadas, perpassam até hoje, nas falas de muitas outras personagens anônimas que circulam em diferentes espaços na busca desta tão "sonhada liberdade". Elas até se consideravam autônomas, mas era uma autonomia vigiada, controlada ea expressão "A gente fazia o que era possível", reafirma essa questão. A visibilidade concedida a Rosa-dos-Ventos, só foi possível por ela saber inglês e ela fez uso disso para "barganhar" espaços e conquistas. Até quando precisaremos desta afirmativa para nos sentir realmente "livres" dessas agarras que nos prendem e que delas também fazemos uso como modo de subjetivação?

A expressão de Brisa, "dispensar os médicos" traz a conotação de "independência" que Solverbalizou em sua fala. Elas queriam uma Faculdade e, também, um saber respeitado e independente. Com certeza tiveram que provar que tinham condições para isso e as especializações realizadas no exterior proporcionaram, mesmo que ilusória, a "carta de alforria" para elas, o que não é diferente, em muitas situações, nos dias atuais, como por exemplo, a consulta de enfermagem.

Além disso, com a introdução das teorias de Enfermagem trazidas dos EUA, a enfermeira procura dar visibilidade e trazer cientificidade para o seu fazer:

(...) muitas aspirações, necessidades, algo que eu sentia e não conseguia e, talvez a teoria de como nomear esses sentimentos que eu tinha, eu encontrei respaldo nas teorias da enfermagem. (SOL)

Poderia dizer que a aceitação da intelectualização da enfermeira começou nesse período, quando buscou a partir das teorias um corpo de conhecimento científico para ela:

Um ganho muito forte na enfermagem foi a construção teórica, teorias de enfermagem, porque havia situações em que nós percebiamos que era importante mudar, mas a nossa fala somente, às vezes, não trazia uma convicção. Os embasamentos teóricos, que passaram por um crivo internacional, muitas vezes, davam sentidos, concretizavam essas teorias de enfermagem, concretizava aspirações que a gente tinha, mas que não se via com autoridade teórica para falar sobre esse assunto. Então as teorias de enfermagem contribuirram muito. (SOL)

Desta forma, o saber que a Enfermeira vai construindo e que é aceito de uma certa forma, passa pela reafirmação de uma figura de endosso, alguém que pode falar, no caso, grupos que pertenciam a países do Hemisfério Norte e nós, como subsidiárias. Quem fala tem que ter passado por uma apropriação que vem de fora, de um curso no Exterior, que endossa o saber da área da Saúde. Da mesma forma, há um saber que se cria nesse movimento de submetimento teórico para fazer valer as práticas, até então desenvolvidas.

Como referido, cria-se um saber que parte, em um primeiro momento desse processo de submissão teórica e, inclusive espacial, em relação a alguns centros de saber do continente americano. São as positividades ${ }^{1}$ das relações de poder e do próprio saber.

Mas, de que teorias estão falando? Essa "nova" fase da enfermeira, que poderia chamar de intelectualização, pelo viés das teorias de Enfermagem, nos informa que antes, tudo que faziam não estava embasada em uma teoria?

Nos utilizamos das escritas de Foucault ${ }^{(8)}$, para esquadrinhar essas questões e analisar sobre a (des)construção dessas teorias, mesmo que, nesse momento, de forma sucinta.

O que se tenta explicar é como a enfermeira buscou transformar um saber desqualificado, considerado não científico para científico. Mas, ao transitar por essa rota, trago novamente Foucault para nos auxiliar nessa compreensão. Para ele a ciência passa a existir a partir do século XVIII quando ocorreu um disciplinamento dos saberes e no qual a Universidade teve um papel fundamental em uniformizá-los. O que isso quer nos dizer? Que a Enfermagem, a partir do momento que cria uma categoria de nível superior, adquire um status de ciência, porém, só isso não foi suficiente. Foi preciso teorizar essa profissão, fazer circular em todos os espaços, conceituando até o que era ser enfermeira.

Surge então, as teorias de Enfermagem (As teorias de Enfermagem surgem nos EUA, mais fortemente, a partir da década de 1950. "É o enfoque da construção do corpo de conhecimentos específicos da Enfermagem, expresso por uma terminologia variada como: a natureza específica da 
Enfermagem, a formalização dos conceitos e teorias, a construção de marcos teóricos de referência, de modelos etc"(1)) nos EUA, e no qual enfermeiras brasileiras encontraram, um espaço para se projetar, sair de uma prática artesanal, um intelectual "amador" para um universal, como se com isso tudo se resolvesse.

Para Foucault, essa relação de teoria e prática sempre foi pontuada como sendo a prática decorrente da teoria; entretanto, ele nos sinaliza que a prática tem primazia sobre a teoria, ou seja "(...) a teoria não expressará, não traduzirá, não aplicará uma prática, ela é uma prática. Porém local e regional, (...) não totalizadora"(8).

Partindo desta premissa, a enfermeira, ao ocupar um espaço na área da Saúde, utilizou um saber instituído pelos práticos/auxiliares de Enfermagem, onde predominavam as técnicas. Ao invés dela fazer deste saber prático, a construção do seu referencial teórico e ampliá-lo, ela o renega, desqualifica, deixando para os práticos a continuidade desse fazer. Qual o caminho que ela percorre? Um dos caminhos ${ }^{(1)}$ é a teorização do cuidado, agregando nas teorias outras áreas do conhecimento como a Psicologia, Antropologia, Sociologia.

Ao agregar outras áreas do conhecimento, além da Biologia, Medicina, Fisiologia, ela procura ampliar o cuidado para entender melhor e desenvolver um plano de assistência, ainda que centrado na doença. Nesse sentido, observa-se que cada teoria apresenta quatro conceitos mais significativos que vão determinar a sua prática, são eles: o homem ou o indivíduo; a sociedade/o ambiente; a saúde; a enfermagem.

"Dentre esses quatro conceitos, o centro da prática da enfermagem é 0 indivíduo. É a partir do paciente que surgem os demais conceitos de enfermagem. Sem qualquer um deles, a enfermagem não pode evoluir, seja como ciência, seja como um campo para a prática profissional"(9).

Um exemplo que poderia clarificar melhor a utilização das teorias, nesse período, seria o que Sol trouxe em seu discurso:

(...) Essa questão do autocuidado, que a pessoa no hospital já deve saber ou no posto de saúde, se tomar essa medicação quais os efeitos colaterais que terá ou não. A Wanda Horta que pensou nas necessidades humanas básicas e que também trouxe as questões das condições sociais do paciente, que ele precisava do acompanhante com ele e os níveis de dependência, nível I, II, III e IV, paciente com autodependência, o familiar precisa aprender o que significa. Isso fez com que a gente começasse a trazer, porque antes o horário das visitas era uma hora, uma ou duas vezes por semana, geralmente era aos domingos e as quintas. As pessoas que vinham fora de hora tinham que pagar, comprar um cartão para ter direito a visitar a família. Neste sentido, muitas aspirações, necessidades, algo que eu sentia e não conseguia e talvez a teoria de como nomear esses sentimentos que eu tinha, eu encontrei respaldo nas teorias da enfermagem. A Orem, que tive oportunidade de fazer curso com ela, a Vanda Horta que fui aluna, a Leininger 4 também fiz cursos com ela e pude entender porque com um paciente italiano, a família queria trazer galeto e polenta e isso começou a quebrar a rigidez no hospital que realmente nós maltratávamos os pacientes. Eu não podia dizer que era um mau trato direto, mas era um ambiente não tão acolhedor e essas teorias propiciaram esse transpor para o hospital essa vida familiar dessa pessoa e não interromper. (...) As teorias de afetividade modificaram muito e a questão do ser humano, da sua afetividade familiar, do seu apoio em crise e várias teorias sobre afetividade, foi outro desempate.

Mesmo que se apresente como um discurso extenso, procuramos não recortá-lo, para mostrar como as teorias vieram preencher uma lacuna na assistência de enfermagem, vista e percebida por algumas profissionais e, além disso, como a Enfermagem se associa as outras áreas de saberes como a Psicologia, para constituir um novo saber, mesmo que seja construído por americanas e distantes da realidade brasileira.
Porém, ao analisar esse discurso, tento olhá-lo a partir de um lugar privilegiado, ao qual poucas tinham acesso e o conhecimento também era pouco divulgado, pois na seqüência da fala de Sol, ela nos lembra que estava no mundo acadêmico e, por isso tinha acesso às teorias por meio dos encontros científicos, de cursos de atualização, como se o saber fosse produto só da academia. Mesmo sendo um lugar privilegiado, não é exclusivo, haja vista que o embate com a família, exemplificado no discurso de Sol, traz a produção de outro saber, construído coletivamente.

Neste contexto, ela expressa de que forma as teorias puderam ser transpostas para a prática e de como a enfermeira agregou ao seu cuidado, outras preocupações que não fossem somente centradas na doença, como a família, a sua cultura, o seu ambiente, a espiritualidade, etc. A fala de Sol nos traduz essas questões:

Eu vivi muito intensamente essa fase de mudança, porque nosso grupo também trabalhou, eu sou de uma geração que a gente trabalhou fortemente e nessas educações que nós fazíamos, muitos detalhes, treinamentos, nós já falávamos sobre a importância de liberarmos visitas e elas (teorias) ajudavam. Isso eu fico muito contente, que eu sou da geração, seguindo até os dias de hoje, mas que nós realmente assumimos a bandeira do compromisso social, da mudança da nossa profissão, isso foi uma bandeira forte, porque alguns da equipe eram ao nosso favor, administradores, médicos, outros não. Havia ainda profissionais que para orientar, ouvir as visitas, eles exigiam que descesse na portaria para conversar com eles. Era uma situação dificil, mas muito interessante, pois recorremos muita a nossa sensibilidade, no nosso compromisso, era alegria para nós quando nós vencíamos essas barreiras.

A introdução das teorias, no universo de trabalho das enfermeiras, motivaramnas a assumirem a bandeira do compromisso social, endossando uma experiência vivida na prática, pois não encontravam suporte teórico ou reconhecimento na sua profissão para mudar algo que as incomodavam. Questiono se essas teorias fossem construídas por enfermeiras brasileiras, será que teriam o mesmo valor e reconhecimento das americanas? Por que as enfermeiras brasileiras, percebendo, na prática, a necessidade de mudança, não tiveram "voz" para propor mudanças?

Ao fazer esses questionamentos nos reportamos aos dias atuais quando ainda se percebe, muitas vezes, a enfermeira assistencial reproduzindo saberes, com pouca reflexão ou propostas de aprimoramento ou até mudanças. $A$ Enfermagem construiu todo o seu saber nas técnicas e, muitas vezes, ele foi construído de forma empírica, permanecendo, por muitos anos, sem nenhuma alteração. Encontram-se, atualmente, em pontos isolados, enfermeiras pesquisando e apresentando novas tecnologias de cuidado, porém, na grande maioria são profissionais ligadas à academia, sem vínculo direto com a assistência. Para as enfermeiras que atuam diretamente com o paciente, essas novas abordagens tecnológicas ainda estão distantes da assistência.

Ao compartilhar essas questões Brisa acrescenta, em relação à academia:

Muitos, depois de terminar o Doutorado, não querem mais a Graduação, querem ficar somente no Pós, desenvolvendo pesquisa, que muitas vezes não qualificam a assistência. Em vez de aproximar, distancia ainda mais. Utilizamos muita a tecnologia no dia-a-dia, entretanto, não a assumimos como algo a ser aperfeiçoado, aprimorado, delegando, muitas vezes competências que são nossas. Acredito que nós temos que nos reunir em grupos de pesquisa e esses grupos se articularem para criar uma filosofia na Enfermagem e a aplicação de pesquisas para melhorar a assistência(...)

Ao trazer o discurso de Brisa a essa problemática, procuramos brechas, vazios que ainda permeiam na academia e na assistência. Há de se encontrar um caminho que possibilite a integração das áreas, sem o assujeitamento de saberes de uma em prol da outra e a pesquisa é uma via que vislumbra essa 
possibilidade.

Ao retornar às questões, em relação às teorias e à "apatia" da enfermeira assistencial em continuar a ser uma mera executora das suas ações de cuidado, nos reportamos às questões apresentadas anteriormente, quanto ao aporte teórico não ter sido compartilhado com todas, pois o acesso estava mais restrito à academia, o que também, de uma certa forma, limitou esse conhecimento a um grupo de profissionais, o que, ainda hoje, é uma crítica presente. Até quando a academia manterá o seu "status quo" de detentora de um saber se, na prática, poucos fazem uso dele? Será que todas as enfermeiras que atuam exclusivamente na assistência conhecem as teorias, defendem e fazem uso delas?

Isso demonstra que ao buscar uma elaboração teórica para a categoria enfermeira, elas monopolizaram um saber específico, o que Foucault ${ }^{(8)}$ denominaria de "intelectual universal", ou seja, aquele que se coloca como detentor de uma "verdade", de uma prática discursiva, em nome de uma consciência que somente ele poderia validar. Renegaram uma prática de "massas", instituída e validada por práticos e auxiliares de enfermagem, distanciando-se deles e ampliando ainda mais um abismo na categoria de enfermagem.

Não se traz aqui a validade ou invalidade das teorias, mas a crítica que se faz é de que elas foram constituídas em um país no qual não existe a divisão de trabalho na categoria de enfermagem. Quem assume o paciente de forma integral é a enfermeira, o que torna mais fácil colocar em prática essas teorias, diferentemente o Brasil, em que o cuidado técnico é desenvolvido pelos técnicos e auxiliares de enfermagem, cabendo à enfermeira a administração desse cuidado.

Portanto, à proposta da construção de um corpo de conhecimentos específicos para enfermagem, que é uma proposta que procura o foro da cientificidade, tem que ser agregada uma alternativa política que leve em conta a constituição do mercado de trabalho da saúde, os modelos de assistência de saúde, as lutas internas dos agentes por uma ação compartilhada no processo de trabalho, o quadro econômico-social e político das sociedades concretas e a viabilização de extensão de cobertura da atenção de saúde ${ }^{(1)}$.

Além das teorias, o processo de enfermagem que também foi desenvolvido por uma teorista americana no final na década de 1950 e tomou força no Brasil, pelas mãos da enfermeira Wanda Horta, na década de 1970, é outro saber constituído a ser discutido. Em seu livro, Processo de Enfermagem, editado em 1979, a autora coloca que a Enfermagem somente iria adquirir autonomia quando integrasse, nas suas ações, o processo de enfermagem como metodologia cientifica. Já se passaram mais de vinte anos e, continuamos em busca de uma tão sonhada autonomia. Será que somente processo de enfermagem daria conta disso? Como o processo envolve cinco fases e tem como objetivo avaliar, planejar, implementar e desenvolver o cuidado, ainda percebo serem poucas as instituições que o utilizam em todas as suas etapas.

Durante a Graduação, a aluna desenvolve e aplica todas as fases, registrando sempre na folha de evolução do prontuário do paciente. Quando inicia sua vida profissional, percebe-se que, muitas vezes, não dá continuidade a essa ação de cuidado, verbalizando falta de tempo. Já que é enfatizado na faculdade, ser este um método norteador e sistematizador do cuidado, por que a enfermeira não desenvolve e valoriza essa atividade, como imprescindível, na sua práxis diária? Da mesma forma poderia citar o exame clínico que envolve habilidades de ausculta, palpação, percussão e inspeção. São dados importantes para uma avaliação e planejamento do cuidado, que a enfermeira deve fazer diariamente. Entretanto, a mesma aluna que durante a Graduação fez várias vezes o exame clínico, depois de formada, não o desenvolve mais da mesma forma, alegando falta de tempo.

Essa falta de tempo, muitas vezes justificada pelas questões administrativas, burocráticas a serem resolvidas no seu ambiente de trabalho, distanciam cada vez mais a enfermeira do paciente. E ela, ao se distanciar, inviabiliza desenvolver o processo de enfermagem, pois não tem como fazêlo sem estar próximo a ele. Um dos fatores deste distanciamento poderia ser o que Sol coloca em relação à sobrecarga de trabalho que a enfermeira tem enfrentado na área hospitalar:

(...) tudo canaliza para ela (enfermeira) na questão da cobrança e isso não pode acontecer. É muito, muito (...) Imagina uma profissional de enfermagem que coordena uma equipe, tem $40 \%$, toda a questão gerencial administrativa, toda a questão de discussão com cada profissional sobre o paciente, como é que essa pessoa pode? Acho que ela precisa ter "tentáculos mentais", porque eu não sei da onde ela tira essa força, essa vitalidade, exauri. Estou achando que o enfermeiro, que em muitas situações, não são em todos os hospitais, mas ainda está sendo muito exaurida no seu horário de trabalho.

De acordo como está, atualmente, organizado economicamente e administrativamente o hospital, é possivel à enfermeira, conforme o discurso de Sol, dar conta de uma enfermagem que atenda diretamente o paciente, desenvolvendo e supervisionando um plano de cuidados a todos, gerencie uma unidade, promova educação continuada a sua equipe e ainda, consiga pensar e desenvolver novas pesquisas tecnologias? É essa enfermagem que queremos?

Estas são algumas das interrogações que procuramos problematizar ao longo dessa pesquisa, mesmo porque, autores como Deleuze, Guattari, Foucault, entre outros, nos fazem repensar a existência da verdade ${ }^{(11)}$, como absoluta, pois na relação teoria-prática, a constituição de novas formas de saberes está em permanente estado provisório, fazendo com que a prática social da Enfermagem e o objeto de trabalho possam ser questionadas permanentemente.

\section{CONSIDERAÇÕES FINAIS}

Os vários saberes que foram sendo constituídos na trajetória da enfermeira, a partir da década de 1950, no RS, sejam eles denominados de sujeitados, desqualificados, fragmentados, populares, de lutas, científicos, entre outros, estiveram ancorados na construção histórica da profissão, imprimindo, em nosso cotidiano atual, verdades consagradas, impenetráveis e mantenedoras de múltiplos modos de constituição da existência, do si-Enfermagem.

Neste contexto, com a introdução das teorias de Enfermagem, trazidas por enfermeiras brasileiras que realizaram especialização nos EUA, houve um aprimoramento do saber/fazer, agregando ao cuidado outras preocupações que não estivessem somente centradas na doença, mas também, com o contexto de vida do paciente, como a família, a sua cultura, o seu ambiente, a espiritualidade, etc.

Porém, cabe salientar que esse saber ficou mais restrito as enfermeiras que atuavam na docência, propiciando um distanciamento desta para as que atuavam somente na assistência.

Aos poucos se foram incorporando práticas que mudassem, em parte, esse fazer e saber. Entretanto, algumas práticas discursivas ainda permanecem intocáveis, como por exemplo, um ensino fragmentado, à margem das políticas de Saúde e gerando, ainda, em algumas situações, corpos dóceis e disciplinados.

Ao continuar trilhando, nesse espaço geográfico, encontramos brechas, fissuras que possibilitam outros jogos de verdades, no universo acadêmico, entre eles, mesmo que incipiente, a vivência de conceito ampliado de saúde e a articulação de saberes nessa área; o desenvolvimento da integralidade do cuidado como um dos eixos norteadores nas práticas de saúde, propiciando ao usuário/paciente a efetiva participação e escolha do tratamento como um direito seu; maior responsabilidade, por parte dos alunos, docentes e enfermeiras em relação às redes de serviços, não somente na atenção básica, mas em outros cenários, mudando a perspectiva de que o retorno deva pertencer ao usuário/paciente e não ao profissional da Saúde; formar profissionais com capacidade para a integralidade de atenção à saúde, para atuação multiprofissional e com apropriação do SUS. 
Fragmentos da História de Enfermagem: um saber que se cria na teia do processo de submissão teórica

\section{REFERÊNCIAS}

1. Almeida MCP, Rocha JSY. O Saber de enfermagem e sua dimensão prática. São Paulo (SP): Cortez; 1986.

2. Waldow VR. Cuidado humano - o resgate necessário. Porto Alegre (RS): Sagra Luzzatto; 1998.

3. Foucault M. Microfísica do poder. Rio de Janeiro (RJ): Graal; 2001.

4. Foucault M. Vigiar e Punir. Rio de Janeiro (RJ): Vozes; 1999.

5. Ministério da Saúde (BR). Conselho Nacional de Saúde. Comitê Nacional de Ética em Pesquisa em Seres Humanos. Resolução 196 de 10 de outubro de 1996: Diretrizes e normas regulamentadoras de pesquisa envolvendo seres humanos. Brasília (DF): Ministério da Saúde; 1997.

6. Foucault M. Em Defesa da sociedade. São Paulo (SP): Martins Fontes; 1999.
7. Barreira IA, Baptista SS. O movimento de reconsideração do ensino e da pesquisa em história da enfermagem. Rev Bras Enferm 2003;56(6):702-6.

8. Foucault M. Ditos e Escritos IV: Estratégia, Poder-Saber. São Paulo (SP): Florense Universitária; 2003.

9. Torres G. A posição dos conceitos e teorias na Enfermagem. In: George JB. Teorias de Enfermagem: os fundamentos para a prática profissional. Porto Alegre (RS): Artmed; 2000. p. 13-27.

10. Kruse MHL. Os poderes dos corpos frios: das coisas que se ensinam às enfermeiras. Brasília (DF): ABEn; 2004.

11. Ceccim RB. A ciência e a arte de um saber-fazer em saúde. In: Meyer DE, Waldow VR, Lopes MJM. Marcas da diversidade: saberes e fazeres da enfermagem contemporânea. Porto Alegre (RS): Artmed; 1998. p.87-102 